\title{
Experimental Investigation on Material Properties of Ultra - High Performance Fiber Reinforced Concrete in Extreme Conditions
}

\author{
David CITEK ${ }^{1, a}$, Jan FORT ${ }^{2, b,{ }^{*}}$, Zbysek PAVLIK ${ }^{2, c}$ and Jiri KOLISKO ${ }^{1, d}$ \\ ${ }^{1}$ CTU in Prague, Klokner Institute, Solinova 7, 16608 Prague 6, Czech Republic \\ ${ }^{2}$ CTU in Prague, Faculty of Civil Engineering, Thakurova 7, 16629 Prague 6, Czech Republic \\ adavid.citek@cvut.cz, bjan.fort.1@fsv.cvut.cz, cpavlikz@fsv.cvut.cz, djiri.kolisko@cvut.cz \\ ${ }^{*}$ Corresponding author
}

Keywords: UHPC, Elevated temperature, Freeze - thaw, Bond, Strength

\begin{abstract}
The Ultra - High Performance Fibre Reinforced Concrete (UHPFRC) is a very promising modern cementitious material suitable for application in special structures. The knowledge of performance of this relatively new material is limited. This paper deals in more detail with impact of extreme conditions (it means thermal loading) on bond properties between prestressing strands and UHPFRC and an influence of elevated temperature to final material properties of different UHPFRC mixtures. The first part of experimental work was focused on mechanical properties of UHPFRC and UHPC exposure to the high temperature $\left(\mathrm{T}_{\max }=200^{\circ} \mathrm{C}-1000^{\circ} \mathrm{C}\right)$. Tested residual mechanical properties were compressive and flexural strengths, the fracture properties will be presented in this paper. Specimens in the first second experimental part were subjected to the cycling freeze-thaw testing. The relationship between bond behavior of both type of material (UHPC and ordinary concrete) and effect of cycling freeze-thaw tests was investigated. The obtained experimental data serve as a basis for further systematic experimental verification and more accurate information about the significantly higher material properties of UHP(FR)C and its behavior in extreme conditions.
\end{abstract}

\section{Introduction}

Experimental research in the field of UHPC applications is very important. Based on current experience, this relatively new material with excellent mechanical and physical properties allows optimization of design rules of structural members and their details especially with regards to the anchorage length of the reinforcement [1]. Previous experiments that were been focused on the bond behavior between reinforcing bars and ordinary concrete and between prestressing strands and UHPC [2] confirmed the fact, that the excellent characteristics of UHPC material have very important effect on the bond properties. In the relation to this research, the article describes experimental verification of shear stress between prestressing strands and UHPC in extreme conditions. The effect of variable ambient temperature was investigated also on the specimens made from both type of material, UHPC and ordinary concrete $\mathrm{C} 50 / 60$. The specimens were exposed to cycling temperature in the range from $-20^{\circ} \mathrm{C}$ to $+20^{\circ} \mathrm{C}$. The number of cycles varied from 100 to 400 cycles. Degradation of the material and related decline of material characteristics could have very significant impact on values of the bond stress.

Exposition to elevated temperatures $\left(\mathrm{T}_{\max }=200^{\circ} \mathrm{C}\right.$ to $\left.\mathrm{T}_{\max }=1000^{\circ} \mathrm{C}\right)$ impact on degradation of material properties was content of second part of experimental program. High-temperature resistance is one of the particular importance of fire safety [9]. Adding steel fibers to UHPC matrix helps increase the values of compressive strength and mainly flexural strength. The effect of residual strength after high temperature exposure and comparison of steel fibers effect to final strength were main objectives of the second part of the article [4]. Specimens were exposed to temperatures $200-1000^{\circ} \mathrm{C}$ and tested in laboratory condition in loading device in three point bending test. Fracture-mechanical properties as effective fracture toughness and specific fracture energy were calculated from obtained data results and will be published in the future paper. 


\section{Impact of elevated temperatures on material properties of UHPC and UHPFRC}

High-temperature resistance is one of the particular importance because of the fire safety. Therefore, the effect of high-temperature exposure on Ultra-High Performance Fiber Reinforced Concrete (UHPFRC) properties was studied in this part of experimental program. The UHPFRC specimens were exposed to the temperatures level of $200,400,600,800$, and $1000^{\circ} \mathrm{C}$ respectively. The mechanical resistivity against disruptive temperature action is characterized by compressive and flexural strength. The fracture-mechanical properties as effective fracture toughness and specific fracture energy were accessed as well. The exposure of examined material to the elevated temperature led to the increase open porosity in total, increase of volume of bigger pores, and as a consequence to the significant decrease of mechanical strength. The obtained data will find use as an input of material parameters for the numerical modelling of UHPFRC structures exposed to the fire and high temperature action and their damage level.

Experimental program consists of testing of the three different matrix of UHPC material type. The first reference matrix was plain (without fibers), the last two mixtures were reinforced by different volume fraction of the short brass coated steel fibers. This paper deals in more detail with basic difference between reinforced and non-reinforced variant of UHPC so only first UHPFRC I mixture is described in more detail. Mixture design of referent UHPC and first UHPFRC I matrix is shown in tab. 2. The mechanical properties of the fibers are listed in tab. 1. The mixture design of UHPC materials is shown at tab. 2.

Tab. 1 Mechanical properties of short steel fibers

\begin{tabular}{|l|c|c|c|c|c|}
\hline Fiber type & Material & $\mathbf{L}_{\mathbf{f}}[\mathbf{m m}]$ & $\mathbf{d}_{\mathbf{f}}[\mathbf{m m}]$ & $\mathbf{E}_{\mathbf{f}}[\mathbf{G P a}]$ & $\mathbf{f}_{\mathbf{t}}[\mathbf{M P a}]$ \\
\hline Steel fibers & brass coated steel & 13 & 0.2 & 200 & $\geq 2200$ \\
\hline
\end{tabular}

Tab. 2 Mixture design of UHPC and UHPFRC I

\begin{tabular}{|c|c|c|}
\hline Component $\backslash$ Mixture design & $\begin{array}{c}\text { UHPC } \\
\text { [\%] }\end{array}$ & $\begin{array}{c}\text { UHPFRC I } \\
{[\%]}\end{array}$ \\
\hline "CEM II 42,5 & 690 & 100 \\
\hline Sand type I $0-2 \mathrm{~mm}$ & 1235 & - \\
\hline Sand type II $0-2 \mathrm{~mm}$ & - & 1260 \\
\hline Silica fume & 100 & 100 \\
\hline Slag & 80 & 80 \\
\hline Superplasticizer & 40 & 40 \\
\hline Water & 165 & 165 \\
\hline Steel fibers $\left(V_{f}\right)$ & 0 & 120 \\
\hline Bulk density of fresh concrete $\left[\mathrm{kg} / \mathrm{m}^{3}\right]$ & 2400 & 2335 \\
\hline Water to binder ratio w/b [-] & 0.23 & 0.23 \\
\hline
\end{tabular}

The value of the water to binder ratio that is shown in tab. 1 is determined by eq. 1 :

$$
\frac{w}{b}=\frac{m_{w}+m_{p i}}{m_{e}+m_{s f}+m_{g}}
$$

note: $\quad m_{w} \quad$ weight of water $\left[\mathrm{kg} / \mathrm{m}^{3}\right]$

$\mathrm{m}_{\mathrm{pl}} \quad$ weight of superplasticizer $\left[\mathrm{kg} / \mathrm{m}^{3}\right]$

$\mathrm{m}_{\mathrm{c}} \quad$ weight of cement $\left[\mathrm{kg} / \mathrm{m}^{3}\right]$

$\mathrm{m}_{\mathrm{sf}} \quad$ weight of silica fume $\left[\mathrm{kg} / \mathrm{m}^{3}\right]$

$\mathrm{m}_{\mathrm{s}} \quad$ weight of slag $\left[\mathrm{kg} / \mathrm{m}^{3}\right]$ 
Dry aggregates, cement, silica fume, slag and ground quartz were mixed for $120 \mathrm{sec}$, then $75 \%$ of water was added. Remaining $25 \%$ of water was added together with superplasticizer. All components were mixed next $300 \mathrm{sec}$. After this time the short brass coated steel fibers were added and mixed next $120 \mathrm{sec}$. The total volume of the mixer is 50 liters, from each mixture was mixed 35 liters of fresh UHPC.

For each mixture were prepared small beams size 160/40/40 $\mathrm{mm}$ that were casted and cured according to standards for ordinary concrete. Many additional tests were executed (compressive strength on cubes, cylinders, static modulus of elasticity). Only small beams were exposed to high temperatures and tested for residual strength. After three month of curing in the water the samples were stored in laboratory conditions. All samples were dried out $\left(105^{\circ} \mathrm{C}\right)$ to the steady state humidity before heating before the bending tests. The small beams were heated in electrical furnace without openings.

The rate of heating was $1^{\circ} \mathrm{C} / \mathrm{min}$, after reaching the maximum temperature load $\left(\mathrm{T}_{\max }=200,400\right.$, 600,800 and $1000^{\circ} \mathrm{C}$ ) were samples maintained for 90 minutes on the temperature level and after that there were naturally cooled down to the ambient temperature $\left(\mathrm{T}_{0}=20^{\circ} \mathrm{C}\right)[6,7,8]$. The results of mechanical properties of UHPC material exposure to the high temperature are shown at fig. 2 (reference UHPC mixture design without fibers reinforcing), at fig. 3 and fig. 4 for UHPFRC. The comparison between all UHPC mixtures is listed at fig. 5. The small beams without notch were tested at four-point bending test with span $\mathrm{L}_{0}=120 \mathrm{~mm}$.
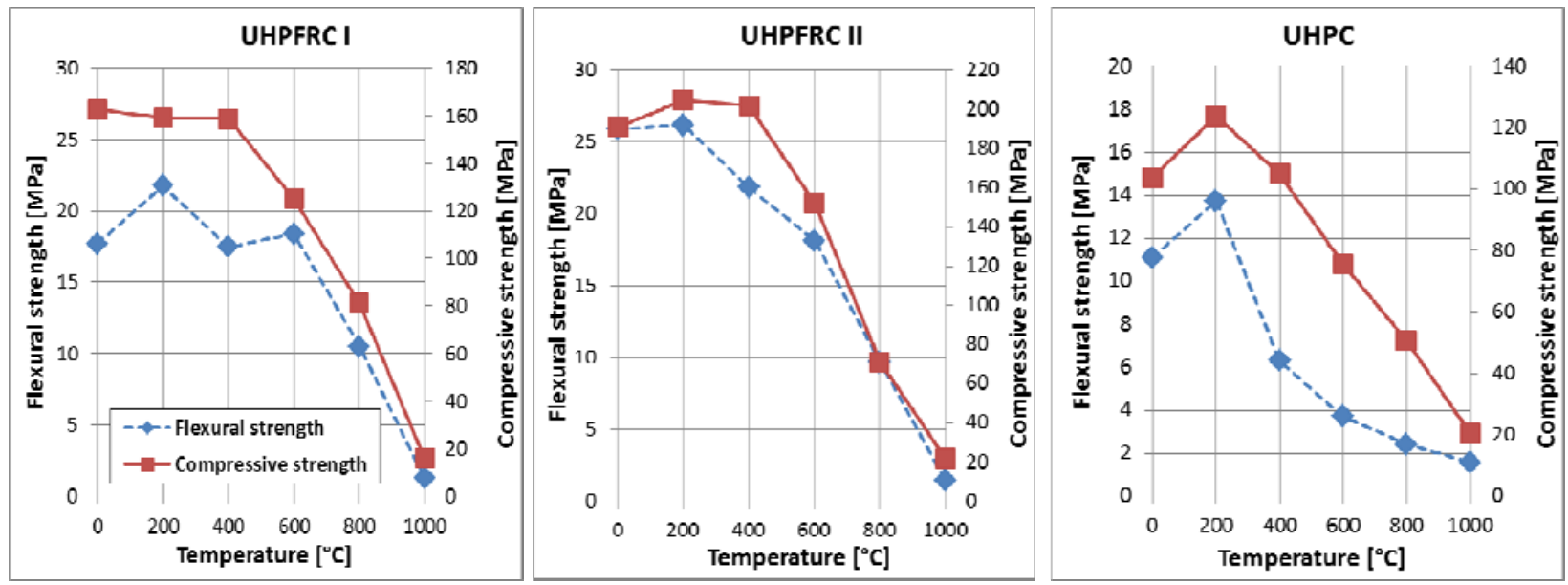

Fig. 1 Comparison between temperature and flexural/compressive strength - different mixtures

The results showed known fact that compressive and tensile strengths of UHPC are higher in mixtures with fibres. The tests of residual compressive strength after high-temperature exposition with rate $0-800^{\circ} \mathrm{C}$ demonstrated that the fact is proportionally the same comparing UHPC and UHPFRC. The same phenomenon was obtained in tests of residual flexural strength of specimens after temperature $0-600^{\circ} \mathrm{C}$. The ratio of compressive strength after $1000^{\circ} \mathrm{C}$ and flexural strength after 800 and $1000^{\circ} \mathrm{C}$ was lower. 

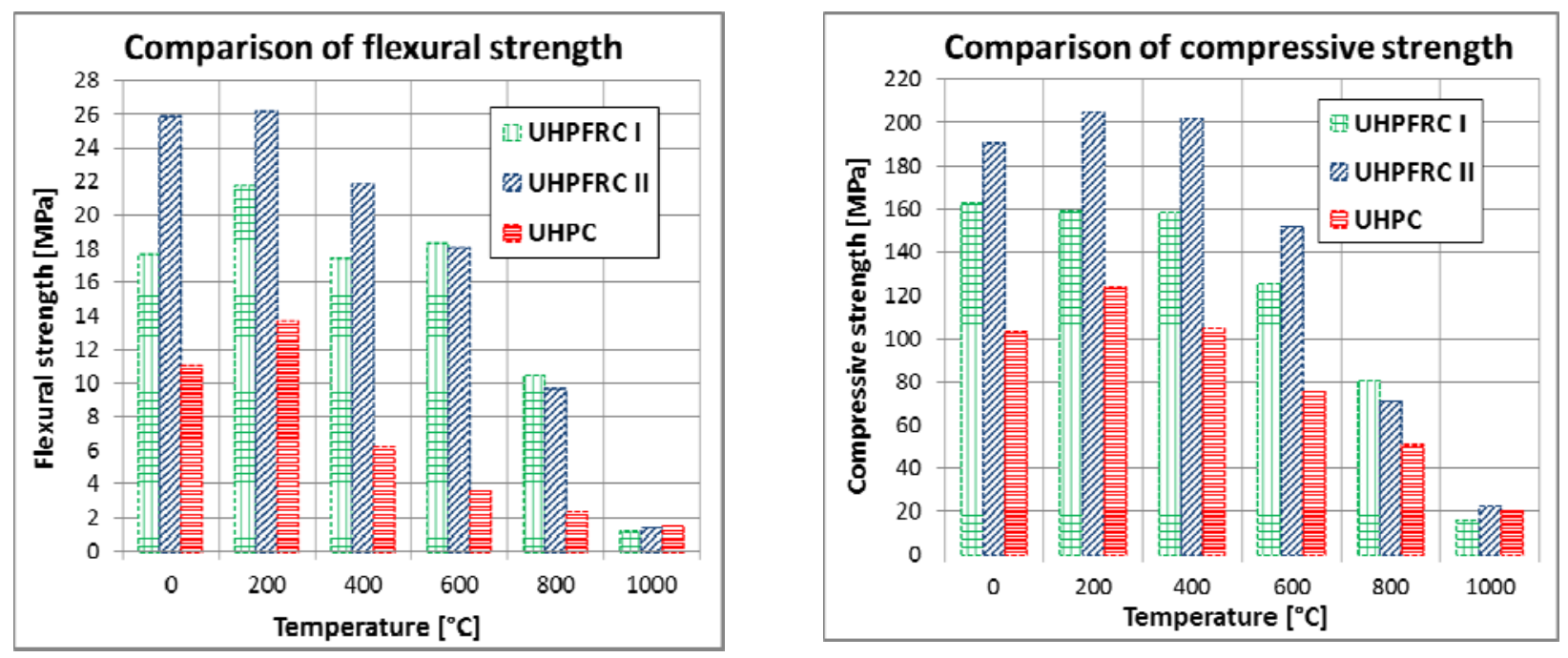

Fig. 2 Comparison of flexural and compressive strength of different UHPC mixtures

\section{Impact of freeze/thawn on bond of prestressing strands and UHPC}

The objective of the main part of experiments was to describe the behaviour of UHPC subjected to a variable thermal stress in more detail. Thermal stress shall be understood here as a cycling of negative and positive temperatures, i.e. freezing and thawing cycles. Specimens (cubes with axially concreted reinforcement according to ČSN 731333 [3] were inserted in cycling device which performed cycles of frost $\left(-20^{\circ} \mathrm{C}\right)$ lasting 4 hours and water setting $\left(+20^{\circ}\right)$ lasting 2 hours. Specimens were initially left in the device for the time of 100 cycles, then 200, 300 and 400 cycles.

Sets of specimens containing three specimens for individual variants were prepared within the experiment. 40 test specimens were made (20 from UHPC and 20 from concrete C50/60) in total. More specimens could not have been produced due to the capacity of the cycling device. Principle of the experiment was placing of half of the specimens in the cycling device and half in the PE foil according to the standard. Cycling started about after 50 days from casting of specimens, so the specimens would be exposed to the environmental effects in a similar age as it could be expected in the practical applications. Until the time of the test, specimens were placed in PE foil according to the standard. After termination of 100, 200, 300 and 400 cycles, relevant specimens were removed and tested together with reference set maintained according to the standard. An assessment of results was fully identical with previous tests - tensile forces were recalculated to average values of shear stress in bond. Individual results of average shear stress in the bond are introduced in following chapters.

Concrete C50/60. Specimens from ordinary concrete C50/60 proved already after 100 freezing cycles a surface damage with fine cracks. Reference specimens maintained according to the standard and tested always at the same time as the specimens after finishing of cycling proved good conformity. The graph shows the average shear stress until $6 \mathrm{~mm}$ slip of the unloaded end of reinforcement is reached.

Specimens after 100 freezing cycles proved during initial slip of the unloaded end of reinforcement a drop of the bond stress to $30 \%$ of values of reference specimens. Maximum reached values in reference specimens was 5.9 $\mathrm{MPa}$ and in specimens after 100 cycles was $2.9 \mathrm{MPa}$. Growing tendency of curves is caused due to the effect of twisting of the prestressing strand when it is pulled out from concrete. The rotation of the strand is prevented by the testing device. This tendency is identical in all tested specimens. In the specimens after 200 freezing cycles a similar trend of overall drop of the bond was observed (the maximum value of average shear stress was about $1.4 \mathrm{MPa}$ ). In specimens after 300 and 400 freezing cycles the surface concrete started to fall off, mainly on edges of the specimen. Overall the bond was remarkably influenced by this degradation - specimens reached only maximum values from 1.3 to $1.6 \mathrm{MPa}$. Also in these cases the stress does not gradually grow - 
concrete surrounding of the reinforcement is crushed during its pulling out. Results of specimens after 300 and 400 cycles are very variable - it was caused by small amount of specimens because of capacity of cycling device. For final test after 400 cycles only two specimens from UHPC and two specimens from C50/60 were tested.

UHPC. Very interesting results of experiment, compared to specimens from ordinary concrete, were observed in specimens made from UHPC. Again, the following graph confirms identity of obtained results from reference sets of specimens tested at the same time as the specimens after cycling. Specimens were identically maintained as specimens from ordinary concrete C50/60 and were subjected to the same number of cycles. Principal point of the experiment are the knowledges that there is no surface rupture of the UHPC specimens after 400 freezing and thawing cycles and even no decrease of average stress in the bond. Fine-grained structure of UHPC in the connection with excellent mechanical properties would resist on a long-term basis to extreme conditions represented undoubtedly by these freezing cycles. Development of average shear stress values in bond for the specimens made from UHPC detailed shows the graph in Fig. 1. Maximum value of the reached shear stress was about $14.9 \mathrm{MPa}$.

The fact, that UHPC specimen after freezing cycles reach locally higher values than reference specimens, can be explained by the method of the specimen treatment. Standard placing of the reference specimens is assumed in the humidity of $60 \%$ - i.e. in PE foil. Cycling is causing repeated watering of specimens thus possibly partially hydrating the cement and improving its mechanical features.

The comparison of behaviour of two different materials in extreme conditions was additional results of the experiment. The following graph in Fig. 3 shows the development of the values of average shear stress of all specimens.

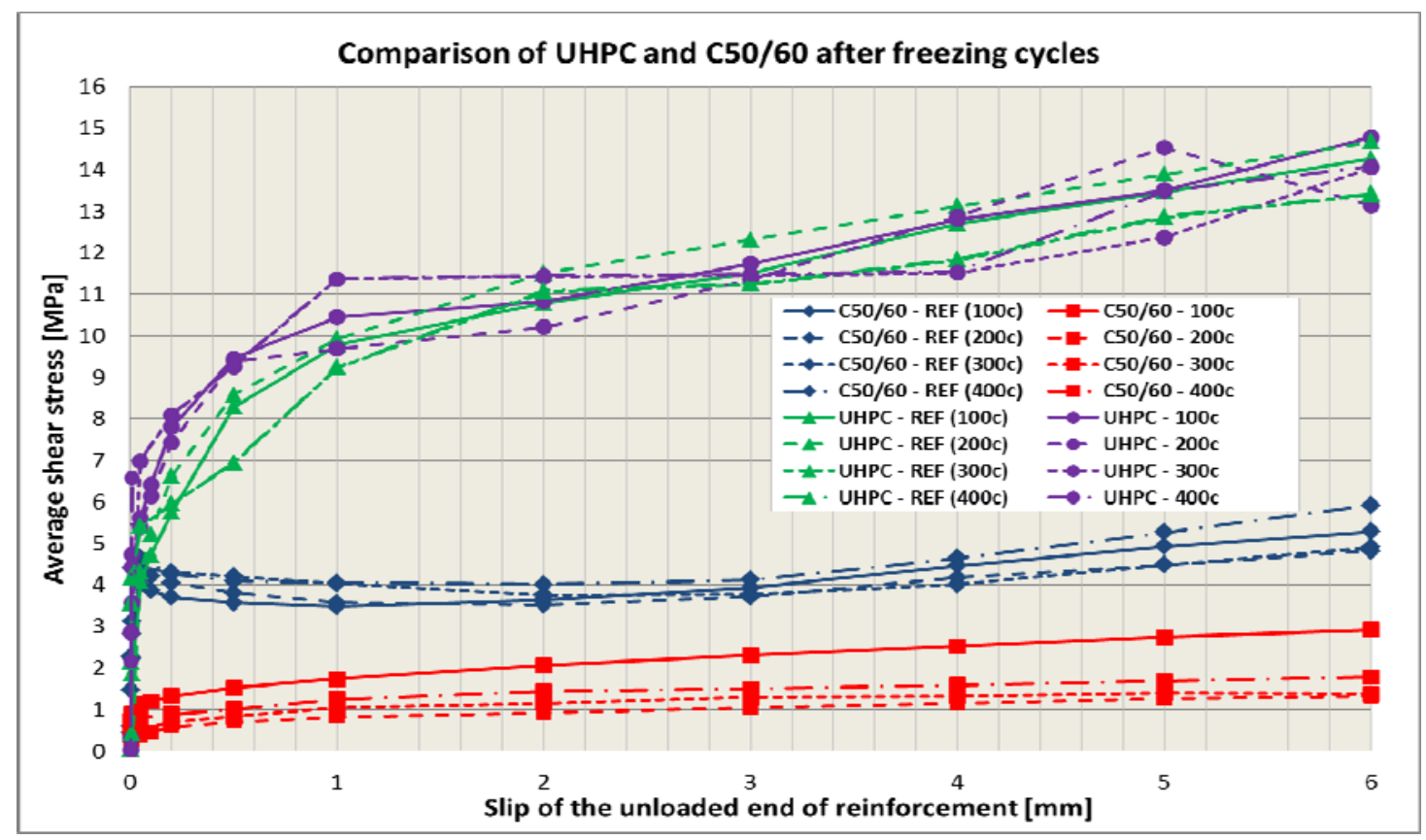

Fig. 3 Overall comparison of UHPC and C50/60 after 100, 200, 300 and 400 freezing cycles

The difference between UHPC and concrete C50/60 in the bond is evident. Reference specimens made from ordinary concrete reach significantly lower values of average shear stress which was already proven by previous research. The most important fact is that extreme conditions do not cause degradation of UHPC specimens or reduction of the bond. On the contrary, specimens from ordinary concrete degrade and their bond is reduced. Compressive strengths (measured on cubes) of reference 
specimens from UHPC varied in the range from 120 to $140 \mathrm{MPa}$ and strengths of ordinary concrete class C50/60 between 60 to $70 \mathrm{MPa}$.

\section{Summary}

Extreme conditions are crucial factor for durability and resistivity of concrete. The results of thermal-loading of different type of UHPC/ UHPFRC are presented in this paper. The mechanical properties of material exposure to the high temperature are lower for higher temperature loading. Residual flexural and compressive strength after $200^{\circ} \mathrm{C}$ is higher in all three tested UHP(FR)C mixtures than strengths in laboratory temperatures. Effect of fibres to compressive and flexural strength after exposure to temperatures about $800-1000^{\circ} \mathrm{C}$ is reduced to a minimum or almost eliminated. The second part of the experiments showed the differences between the performance of prestressing strands embedded in UHPC and in ordinary concrete under variable environmental conditions. The pull-out tests on the reference specimens finished in accordance with expectations, very similar results were reached almost independently on the age of concrete. The UHPC specimens UHPC showed even better resistance in pull-out tests after a high number of cycles. In contrary, the specimens made of ordinary concrete suffered from the reduction of the bond stress during pull-out tests. A surface damage due to freezing and thawing cycles was observed at the specimens made from ordinary concrete while the specimens made from UHPC remained without any damage after high number of cycles. The experiments confirmed that the durability of structures made from UHPC is significantly higher. Information about the bond significantly higher values of UHPC with the prestressing strands so as to enable efficient design of prestressed elements.

\section{Acknowledgement}

This contribution is the result of the research supported by the research project GAČR 15-05791S. The tests were carried out in laboratory of Klokner Institute, Czech Technical University in Prague.

\section{References}

[1] Čítek, D., Huňka, P., Řeháček, S., Mandlík, T., Kolísko, J.: Testing of Bond Behaviour of UHPC In.: Advanced Materials Research, Vol 1054, pp 95-98, Trans Tech Publications, Switzerland, 2014.

[2] Vítek, J.L., Coufal, R., Čítek, D.: UHPC - Development and testing on structural elements. In Concrete and Concrete Structures 2013, Žilina, 2013, University of Žilina, str. 218-223, ISSN 1877-7058.

[3] ČSN 731333 Testing of bond between prestressing strands and concrete, Vydavatelství norem, Prague, 1989.

[4] Phan L.T., High-Strength concrete at high temperature - an overview. Online at http://fire.nist.gov/bfrlpubs/build02/PDF/b02171.pdf

[5] Abrams M.S., Compressive strength of concrete at temperatures to $1600{ }^{\circ} \mathrm{F}$, ACI SP 25, Temperature and concrete, Detroit, Michigan, 1971.

[6] Recommendation of RILEM TC 200-HTC: mechanical concrete properties at high temperatures - modelling and applications, Part 1: Introduction-General presentation, In Materials and Structures (2007) 40:841-853, doi 10.1617/s11527-007-9285-2.

[7] Schneider U, Schwesinger P (eds) (1990) Mechanical testing of concrete at high temperatures. RILEM Transaction 1, February 1990, ISBN: 3-88122-565-X, 72.

[8] Schneider U, Properties of materials at high temperatures - Concretes. RILEM-Report 44-PHT, 2nd Edn, Kassel, June 1986. 
[9] AFGC, and SETRA: Ultra-High Performance Fibre Reinforced Concrete-Interim Recommendations, France, 2013 